\title{
Mechanical Properties and Deposition Mechanism of Cold-Sprayed CoNiCrAIY/YSZ Cermet
}

\author{
Kang-Il Lee*, Kazuto Sato and Kazuhiro Ogawa \\ Fracture and Reliability Research Institute, Tohoku University, Sendai 980-8579, Japan
}

\begin{abstract}
The properties of agglomerated and sintered powders of the cermet of yttria-stabilized zirconia (YSZ)/CoNiCrAlY and coatings thereof were investigated. Three multimodal cermet powders were prepared with different compositions $(75 \%$ CoNiCrAlY:25\% YSZ; 50\% CoNiCrAlY:50\% YSZ; and 25\% CoNiCrAlY:75\% YSZ) for deposition by a cold-spraying process. Each of the cermet powders was successfully deposited onto a bond-coated substrate by the cold-spray process with low kinetic energy. Each feedstock powder ensured a homogeneous distribution of YSZ powders in the coating layer. The microstructural characterization and phase analysis of the feedstock powders and the as-sprayed coatings were obtained by X-ray diffraction (XRD), scanning electron microscopy (SEM), and energy-dispersive X-ray spectroscopy (EDX). In the XRD and EDX results, the YSZ content in the coating increased with the increase of YSZ content in the powder blend. Against conventional expectations, the deposition efficiency and hardness of the as-sprayed coatings were improved by low gas pressure. In particular, the as-sprayed coatings with more than 50 mass $\%$ YSZ showed decreased cracks in the coating layer. To understand these results, the cermet particles were coated onto Al substrates by cold-spraying. Then, the particles were cut open to observe the bonded cross-sectional surface by focused ion beam (FIB) analysis. [doi:10.2320/matertrans.T-M2016802]
\end{abstract}

(Received June 10, 2015; Accepted December 25, 2015; Published February 25, 2016)

Keywords: cold spray, CoNiCrAlY, yttria-stabilized zirconia, cermet

\section{Introduction}

In gas turbine plants, increased turbine inlet temperature is required to improve the thermal efficiency of the plant and reduce the emission of greenhouse gases, such as carbon dioxide. However, at high temperatures, the Ni-based superalloy gas turbine blades can experience damage and failure by mechanisms such as melting, creep, and high-temperature oxidation. To prevent this damage, the surfaces of gas turbine blades are protected by thermal barrier coatings (TBCs). To obtain a low thermal conductivity, TBCs are generally applied to a superalloy substrate and contain a metallic bond coat and a refractory ceramic top coat. In general, the fabrication of TBC, involves the application of a MCrAlY $(\mathrm{M}=\mathrm{Co}, \mathrm{Ni}$, or both) bond coat to a Ni-based superalloy substrate. A top coat of yttria-stabilized zirconia (YSZ) follows. However, failure of these conventional TBC systems has been reported to mainly result from the thermal expansion mismatch between the ceramic and metal coating layers of the systems. ${ }^{1-8)}$

To overcome this mismatch, functionally graded materials (FGMs) have been introduced into TBCs; these are referred to as FGM TBCs. FGM TBCs were first proposed in order to obtain a material capable of withstanding the severe thermomechanical loading that occurs in structures and fusion reactors in spacecraft systems, ceramic engines, gas turbines, and diesel engines. The unique idea of FGMs lies in the concept of pairing heat-resistant ceramics on the hightemperature side with tough and high-thermal- conductivity metals on the low-temperature side, to furnish the necessary mechanical toughness. The composition gradually varies from ceramic to metal. However, the fabrication of highquality FGM TBCs proved to be very difficult by such methods as thermal spraying and spark plasma sintering (SPS), as the materials differed so dramatically in melting

*Corresponding author, E-mail: lee-kang-il@rift.mech.tohoku.ac.jp temperature, density, and porosity. While the concept of FGM TBCs itself is intuitive, the fabrication of a fine mixture of ceramics and metals with a compositional gradient is quite difficult. Several processing techniques have been explored, including plasma spraying, powder metallurgy, and in situ synthesis. Despite these explorations, the optimum process for the fabrication of FGM TBCs still remains unknown. ${ }^{8-12)}$

In this study, the cold-spray technique was applied to the fabrication of cermet coatings. Cold-spraying is a relatively new technique suitable for forming coatings as well as thick depositions. Its process entails the exposure of a metallic or dielectric substrate to a high-velocity $(300-1500 \mathrm{~m} / \mathrm{s})$ jet of small (micron-scale) particles, accelerated by a supersonic jet of compressed gas. In the cold-spray process, the powder particles are accelerated by the supersonic gas jet at a temperature that is always lower than the melting point of the powder material, resulting in the formation of a coating from solid-state particles. Therefore, this process has the advantages of dense deposition, high deposition efficiency, and minimal oxidation. ${ }^{13-16)}$

Several advantages exist in manufacturing FGM-TBC using cold-spraying. First, the production cost is very low and deposition efficiency is very high, compared to other methods such as plasma spraying, ${ }^{8-11)}$ SPS, and detonation gun. ${ }^{12)}$ Next, almost no oxide phase exists to cause failures such as delamination and spallation, because the coatings can be manufactured under the melting temperatures of their component materials. Finally, while FGM-TBCs conventionally require different coating process or conditions caused by the different melting temperature and coating conditions for YSZ and CoNiCrAlY powders, the cold-spray system permits one process coating, since the coating condition may be adjusted by manipulating only the gas pressure. Because of these advantages, the cold-spray system is believed to be well-suited for FGM TBC production.

Here, a cermet powder is used to produce a FGM TBC with a constant rate in each layer. Cermet powder is a 

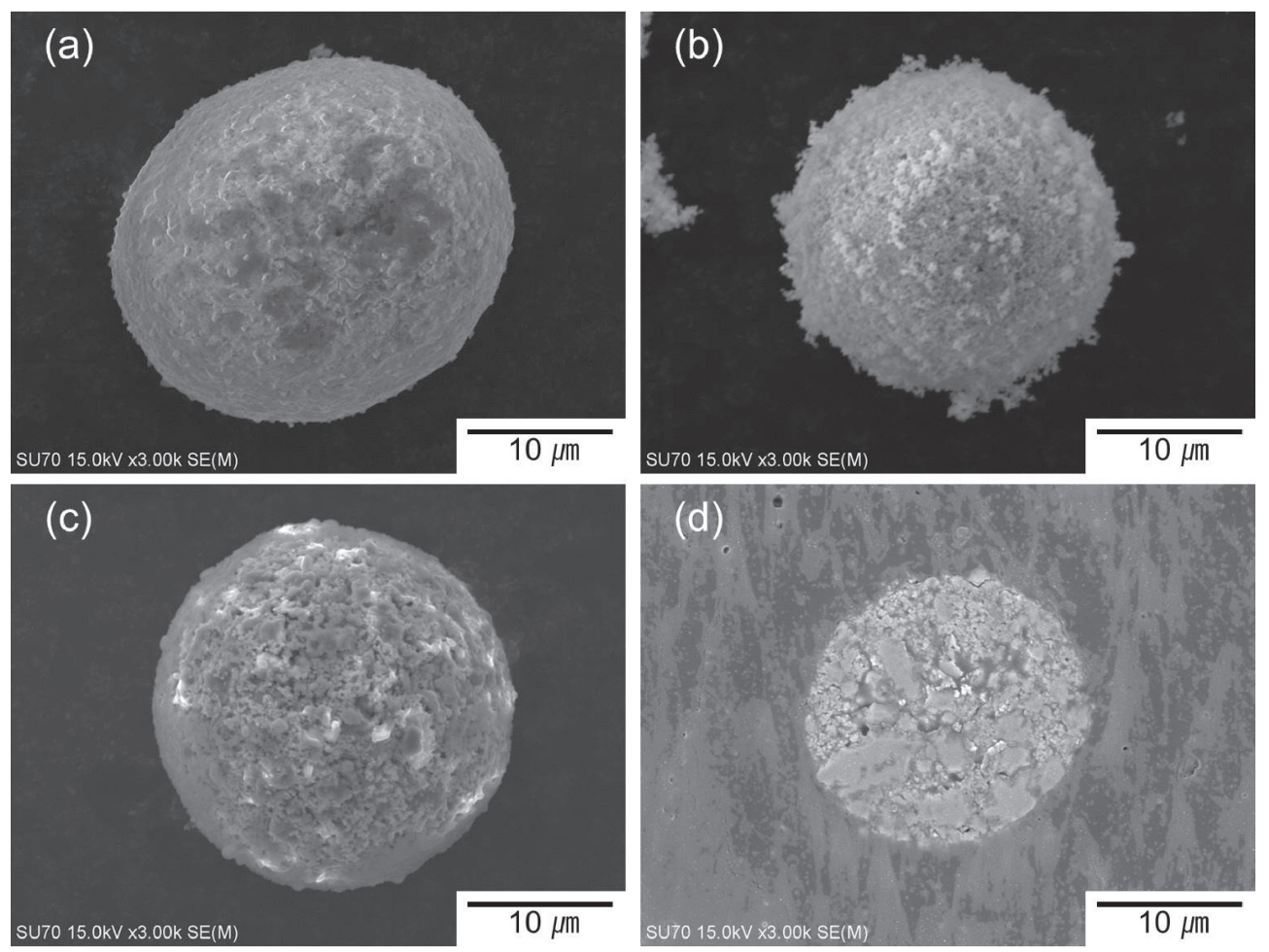

Fig. 1 The morphology of the particles: (a) CoNiCrAlY alloy; (b) 4 mol\% YSZ; (c) 50Y-cermet; and (d) cross-section of 50Y-cermet.

composite material composed of ceramic and metallic materials. Cermets are ideally designed to have the optimal properties of both ceramics, such as high temperature resistance and hardness, and metals, such as the ability to undergo plastic deformation. In the past, many studies have been conducted on the deposition of cermet powder coatings by the cold-spray system. ${ }^{17-19)}$ In this study, the possibility to produce FGM TBC using a cermet with the cold-spray system is confirmed by studying the mechanical properties and deposition mechanism of cold-sprayed CoNiCrAlY/YSZ cermet.

\section{Experimental Procedure}

The polycrystalline Ni-based superalloy Inconel 738LC was used as a substrate. Prior to cold-spray, the substrates were subjected to a grit-blasting process using $\mathrm{Al}_{2} \mathrm{O}_{3}$ media $100 \mu \mathrm{m}$ in diameter to clean and roughen the surfaces, thereby increasing their adherence. CoNiCrAlY as a bond coat was deposited by cold-spraying under identical conditions using spherical Co-32Ni-21Cr-8Al-0.5Y (AMDRY 9951, 5-37 $\mu \mathrm{m}$, Sulzer Metco, USA) powder particles. In addition, these CoNiCrAlY powders and $4 \mathrm{~mol} \% \mathrm{YSZ}$ powders (TZ-4YS, $70 \mathrm{~nm}$, Tosoh, Japan) were used as the primary feedstock to manufacture cermet powders including YSZ contents of 25, 50, and 75 mass $\%$. The mechanically agglomerated and sintered cermet powders of YSZ/ CoNiCrAlY, henceforth referred to as 25Y-, 50Y-, and $75 Y$-cermet, were manufactured by Fujimi Incorporated (Kagamihara, Japan).

The cold-spraying of a homogeneous mixture of CoNiCrAlY and YSZ particles is difficult because of the species' large density difference. To avoid this, spherically agglom-

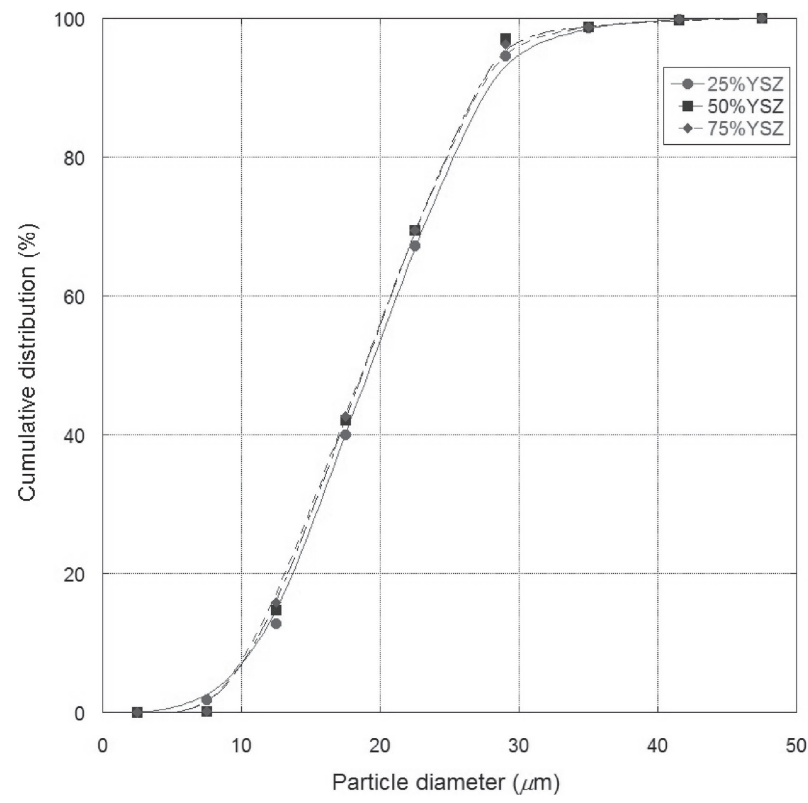

Fig. 2 The particle size distribution of the Y-cermet powder composites.

erated CoNiCrAlY/YSZ composite powders were used. The feedstock powder, with its highly porous and spherical shell morphology, is displayed in Fig. 1. Small YSZ particles $(90 \mathrm{~nm})$ are bonded to each other in a coating on the CoNiCrAlY particle. The measured particle size distribution is provided in Fig. 2. Table 1 summarizes the composition of the feedstock 25, 50, and 75 mass\% cermet powders for coldspraying (Cold spray; PCS-800, PLASMA GIKEN Co. LTD., Japan).

The bond coat was manufactured using $\mathrm{He}$ gas with a gas temperature and pressure of $600^{\circ} \mathrm{C}$ and $3.0 \mathrm{MPa}$, respectively. 
Table 1 Characteristics of the feedstock powders.

\begin{tabular}{ccc}
\hline & $\begin{array}{c}\text { CoNiCrAlY } \\
\text { (mass\%) }\end{array}$ & $\begin{array}{c}\text { Proportion of YSZ } \\
\text { (mass\%) }\end{array}$ \\
\hline 25Y-cermet & 74.4 & 25.6 \\
50Y-cermet & 50.1 & 49.9 \\
75Y-cermet & 30.2 & 69.8 \\
\hline
\end{tabular}

Table 2 Cold-spraying parameters of Y-cermet coatings.

\begin{tabular}{|c|c|c|}
\hline Propellant gas & \multicolumn{2}{|c|}{$\mathrm{N}_{2}$} \\
\hline Pressure of propellant gas (MPa) & 3 & 4 \\
\hline Pressure of powder feed gas (MPa) & 3.1 & 4.1 \\
\hline Temperature of propellant gas $\left({ }^{\circ} \mathrm{C}\right)$ & \multicolumn{2}{|c|}{600} \\
\hline Traverse speed $(\mathrm{mm} / \mathrm{s})$ & \multicolumn{2}{|c|}{50} \\
\hline Distance from exit of nozzle to substrate (mm) & \multicolumn{2}{|c|}{20} \\
\hline
\end{tabular}
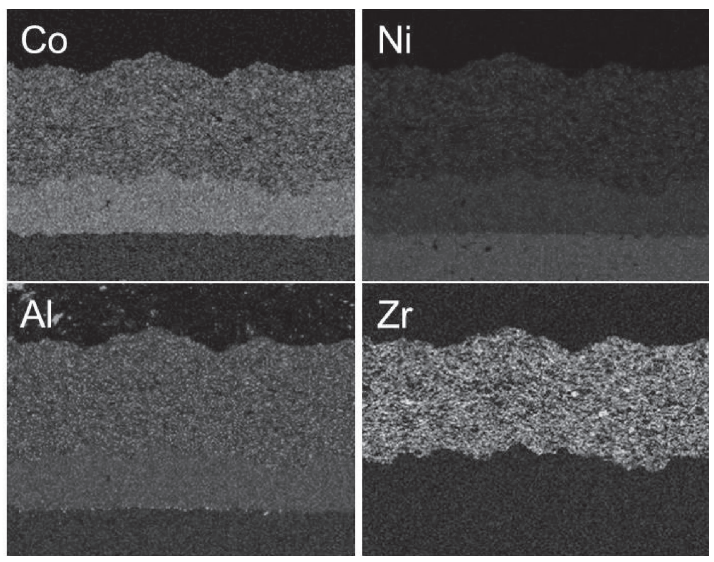

Fig. 3 Cross-sectional SEM image of the microstructure of the as-sprayed 25Y-cermet coatings and corresponding EDX mapping.

Other spraying conditions included a powder feeding rate of $12.4 \mathrm{~g} / \mathrm{min}$, a traverse speed of $50 \mathrm{~mm} / \mathrm{s}$, and a stand-off distance of $20 \mathrm{~mm}$.

The present study focuses on the development of YSZCoNiCrAlY cermet coatings through the use of a low-cost, low-temperature cold-spray system. For this study, the spraying conditions and the coating parameters of Y-cermet coatings are summarized in Table 2.

The samples were mounted in a phenolic resin and manually mirror-polished for scanning electron microscopy (SEM) observation and energy-dispersive X-ray spectroscopy (EDX) analysis. The microstructures of the coating layers were examined by a field-emission SEM (FE-SEM; SU-70, Hitachi, Japan) equipped with EDX. The EDX analysis was performed to evaluate the local elemental distributions in the coating layer.

The micro-hardness value of the coatings was measured by Vickers indentation (Shimadzu micro-hardness tester) at a loading over $15 \mathrm{~s}$ of 0.098 and $0.98 \mathrm{~N}$ for the powder and the coating layer, respectively.

The structures of the powder and coatings were analyzed by X-ray diffraction (Maxima_X XRD-7000, Shimadzu, Japan). A Co anode was used at $40 \mathrm{kV}$ and $30 \mathrm{~mA}$; the $2 \theta$ diffraction angle was changed from $20^{\circ}$ to $90^{\circ}$ at a rate of $2^{\circ} / \min$.

\section{Results and Discussion}

\subsection{Microstructures of coatings made of respective powders}

A cross-sectional SEM image and the EDX elemental mapping results of the $25 \mathrm{Y}$-cermet coatings on a bond coat deposited by cold-spraying are shown in Fig. 3.
The EDX images depict two clearly distinguishable phases present in the coatings. As shown in Fig. 3, a coating of Y-cermet powder with well-distributed YSZ powders was successfully deposited by cold-spraying. The coatings show a homogeneous microstructure because the feedstock powders were mechanically blended, causing their agglomeration to form the spray particles. In addition, cracks and voids are nearly invisible both at the bonding layer between the coating and the substrate and within the coating layer itself. This confirms that the low-particle-velocity deposition of Y-cermet powder had a significant preventative effect against the rebound energy of the CoNiCrAlY powder, ensuring the even distribution of the YSZ powder.

The different powders were fabricated to confirm the dependence of deposition efficiency and hardness on the YSZ contents and gas pressure by cold-spray processing. The $50 \mathrm{Y}-$ cermet has the highest deposition efficiency of the three combinations at equal deposition conditions. This graph demonstrates the variation in deposition efficiency depending on the material ratio of the cermet powder. In 25Y-cermet, the number of rebounded particles is higher than that in $50 \mathrm{Y}$ cermet because the content of high-hardness metals is greater. With 75Y-cermet, the deposition efficiency is very low because of the excessive ceramic contents in the cermet powder. All powders tend to improve in deposition efficiency at the lower gas pressure. Moreover, although the difference is small, all coatings present higher Vickers hardness at the lower gas pressure. This is likely the result of the cracks and pores generated by the high impact energy at the higher pressure. As shown in Fig. 4(b), the hardness values of the feedstock powders were very low. The Y-cermet powders consist of nano-YSZ and several micron-sized CoNiCrAlY particles joined tightly at high temperatures. However, as 
(a)

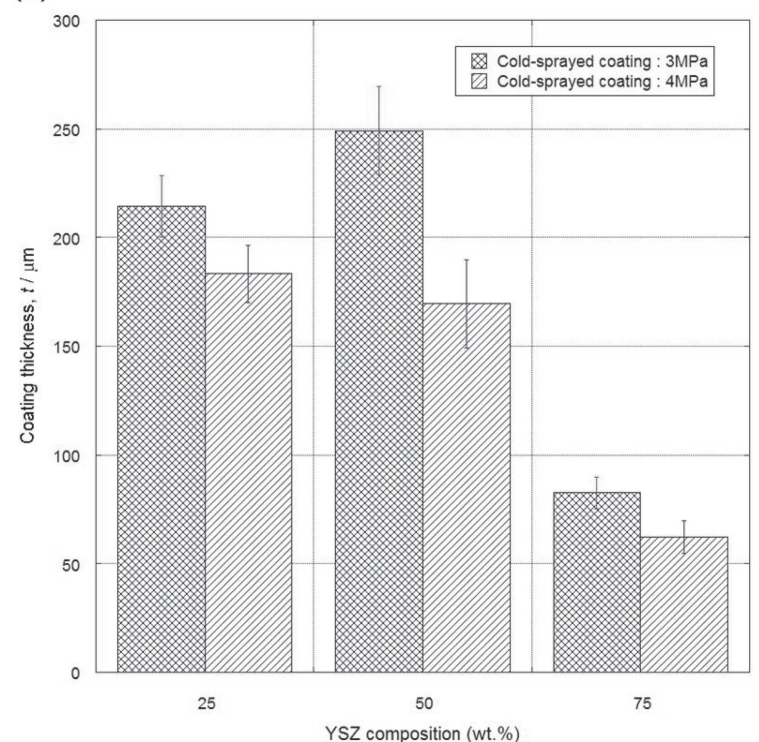

(b)

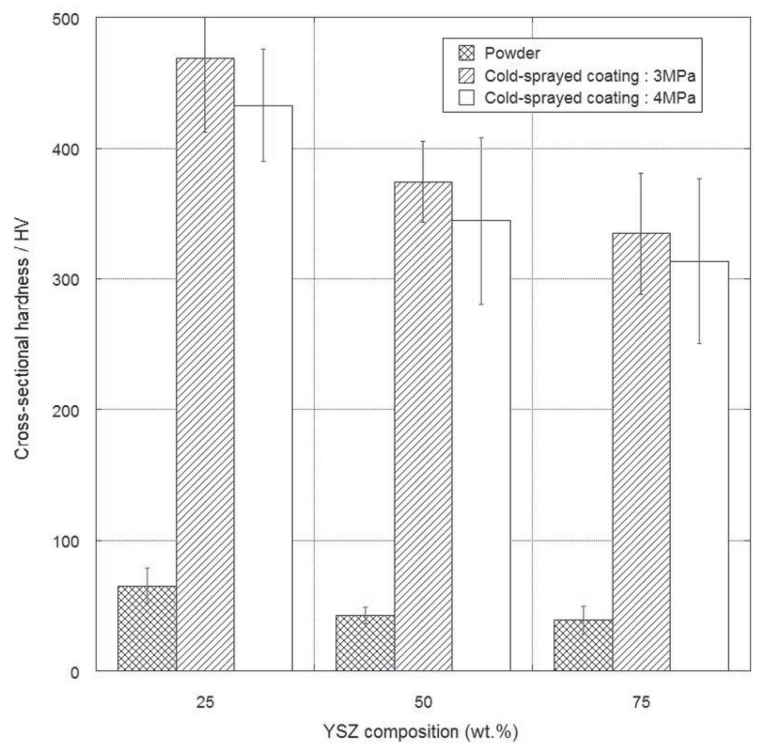

Fig. 4 Thicknesses and Vickers hardness values of Y-cermet powders and as-sprayed Y-cermet coatings manufactured by cold-spraying.

shown in Fig. 1(d), they are determined to have very low hardness due to the weak binding strength and the presence of pores in the powder particles. Meanwhile, the hardness of the coatings deposited by cold-spraying is 5 times greater than that of the powders. As observed, the hardness of the Y-cermet increases by the powder's compression during the cold-spray process.

In general, the hardness and deposition efficiency decreases as the content of nano-YSZ increases. This implies that Y-cermet powders must have their coating conditions changed depending on the nano-YSZ content of. As observed from the results, better-quality coatings can be obtained with lower gas pressure.

Consequently, different manufacturing conditions, depending on the YSZ contents, are necessary in order to obtain high-quality coatings.

Figure 5 shows higher-magnification SEM views of the cross-sections of the Y-cermet coatings. The EDX analysis
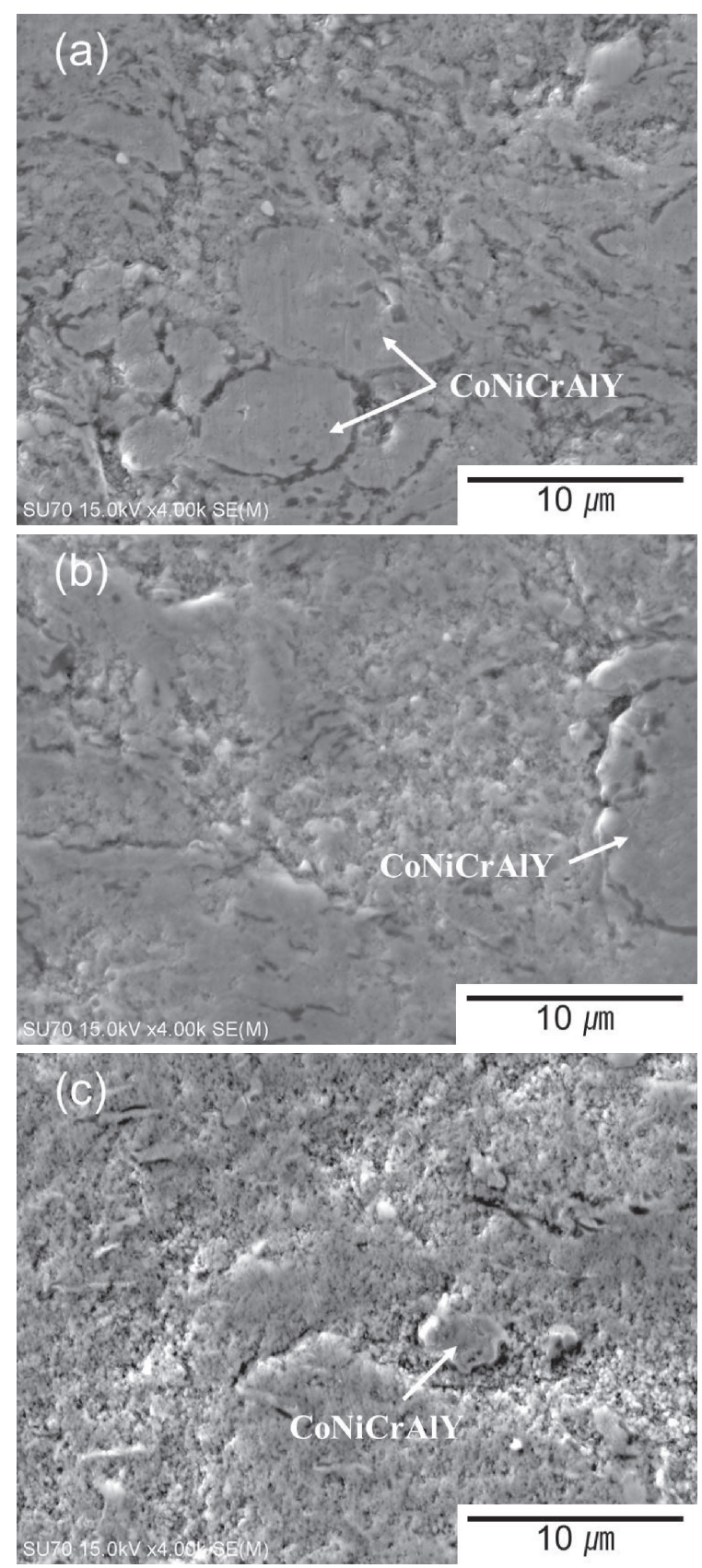

Fig. 5 Higher-magnification cross-sectional micrographs of (a) 25Ycertmet, (b) 50Y-cermet, and (c) 75Y-cermet.

results are almost identical to those of Fig. 3, indicating that bright particles are YSZ and the large dark areas are CoNiCrAlY particles, as indicated by arrows in Fig. 5. As expected, CoNiCrAlY particles are surrounded by nanoYSZ, indicating that nano-YSZ prevents the rebound of CoNiCrAlY. All Y-cermet powder types present little pore formation. In general, pores are not generated when the powder interface is completely connected via the very high kinetic energy of the cold-spray process. As shown in Fig. 5, fine CoNiCrAlY particles are observed in the coating layers from all compositions of feedstock powder. As the composition of YSZ in the feedstock increases, more YSZ particles become fragmented into finer pieces, regardless of the location within the coating. 

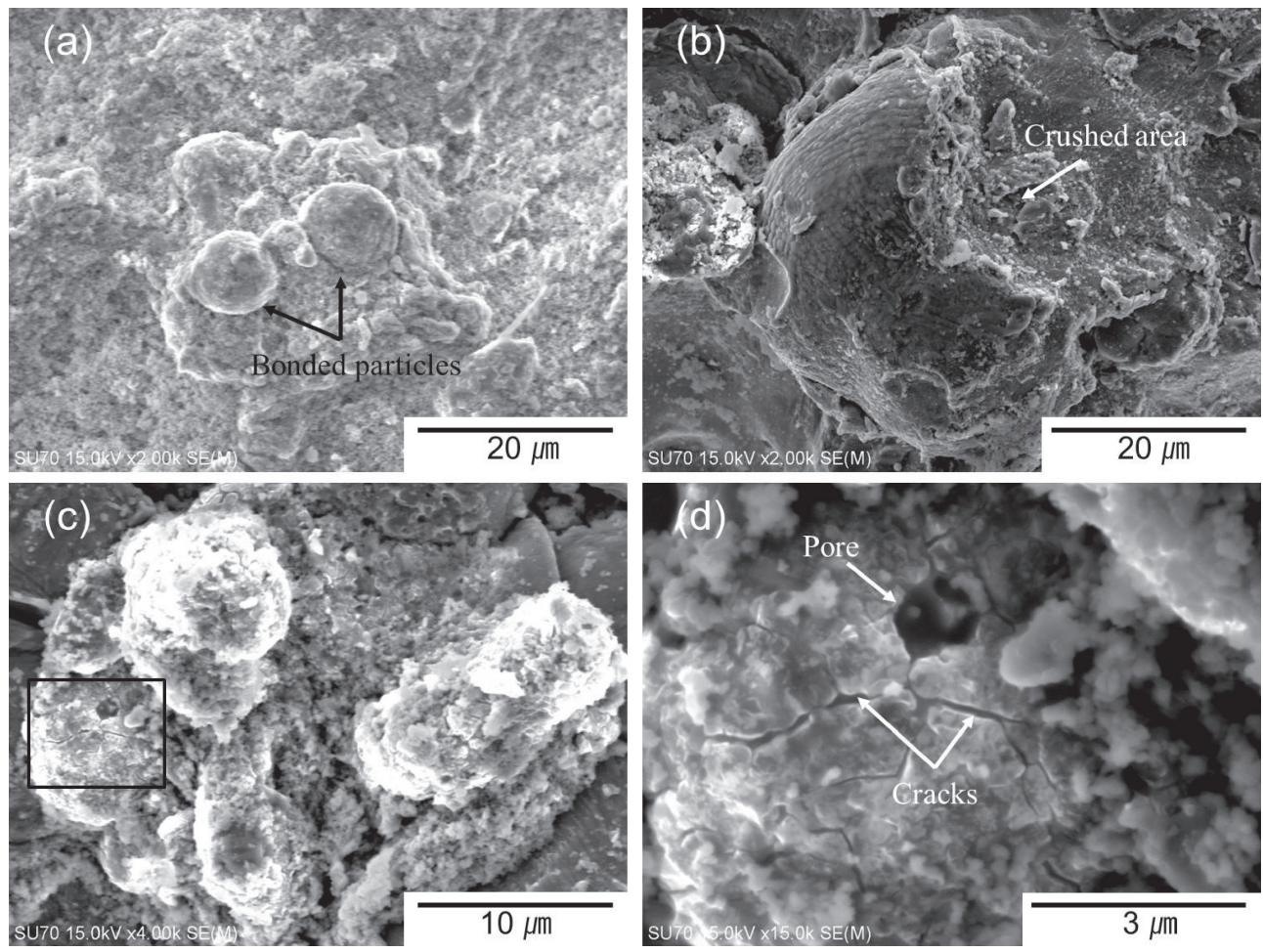

Fig. 6 The morphology of as-sprayed 25Y-cermet particles: (a) surface morphologies of Y-Cermet coatings; (b) bonded particle; (c) exploded particle, and (d) rebounded particle.

\subsection{Particle deposition behavior of CoNiCrAIY/YSZ cermets}

Figure 6 shows the morphology of the as-sprayed particles on the CoNiCrAlY coated substrate. In Fig. 6(a), the deposited surface is observed to be very irregular; it appears almost crushed by its high impact energy. To confirm the morphology of the deposited Y-cermet powders, the particles were sprayed rapidly on the CoNiCrAlY-coated substrate. As shown in Fig. 6(b)-(c), the cold-sprayed particles show morphologies that differ significantly from that of a general metal coating. During cold-spraying, the high-velocity impact from the high-pressure gas causes significant plastic deformation of the feedstock powder, leading to the material's densification. However, Y-cermet particles do not experience plastic deformation as general metal particles do. In particular, when the Y-cermet particles make contact with the substrate, the Y-cermet particles break apart and a significant fraction of concentrated YSZ region.

In the present study, clear observation of the particles on the CoNiCrAlY coating is difficult because of the particles' irregular surfaces and pores, as shown in Fig. 6. For a different view, the Y-cermet particles were deposited on polished Al substrates to determine the coating mechanism by the cold-spray process. Figure 7 shows the morphology of these as-sprayed particles. The Y-cermet particles form so many craters that the polished $\mathrm{Al}$ surface becomes dimpled after cold-spraying. As shown in Fig. 7(d), some nano-YSZ particles may be trapped inside the craters, but no accumulation above them occurs to increase the coating thickness. Generally, the metal particles either bind to the surface or rebound in accordance with their velocities and densities. However, atomized Y-cermet particles are observed to have exploded as a result of their high impact energy in these experiments. As shown in Fig. 7(a), exploded particles or craters occur mostly with particles of average size, whereas particle under $20 \mu \mathrm{m}$ in size generally bind to the surface as a result of their low impact energy on the Al substrate. Figure 7(b)-(d) show magnified images of the cermet particles within the coatings, including bonded, exploded, and rebounded particles, respectively. In this experiment, the craters indicating low deposition efficiency are observed most frequently as shown in Fig. 7(c). However, YSZ particles are observed inside the craters left by rebounded particles. This indicates that the agglomerated powder explodes by its high impact energy.

The particles were cut by focused ion beam (FIB) to observe the interface of the bonded area and investigate the deposition mechanism. Figure 8 shows the cross-sections of particles bonded on the $\mathrm{Al}$ substrate. To prepare the specimens by FIB, a $1-2 \mu \mathrm{m} \mathrm{W}$ layer was deposited onto the particles. Then, the particle was cut by FIB using a $520 \mathrm{kV}$ ion beam. To polish the cross-section, its area was treated for 5 min using a $150 \mathrm{kV}$ ion beam. Figure 8 (a) shows the crosssection of a sprayed CoNiCrAlY particle. As observed in the image, CoNiCrAlY is bonded with the induced transformation of the $\mathrm{Al}$ substrate, as a result of the very high hardness of the superalloy particle. The particle also experiences transformation; however, the particle is not destroyed. Meanwhile, in case of Y-cermet powder in Fig. 8(b)-(d), the particle is confirmed to be destroyed on collision with the substrate. This indicates that the Y-cermet cannot withstand the impact energy as a result of its low hardness. With ceramic materials, their deposition is commonly known to be very difficult because of their lack of 

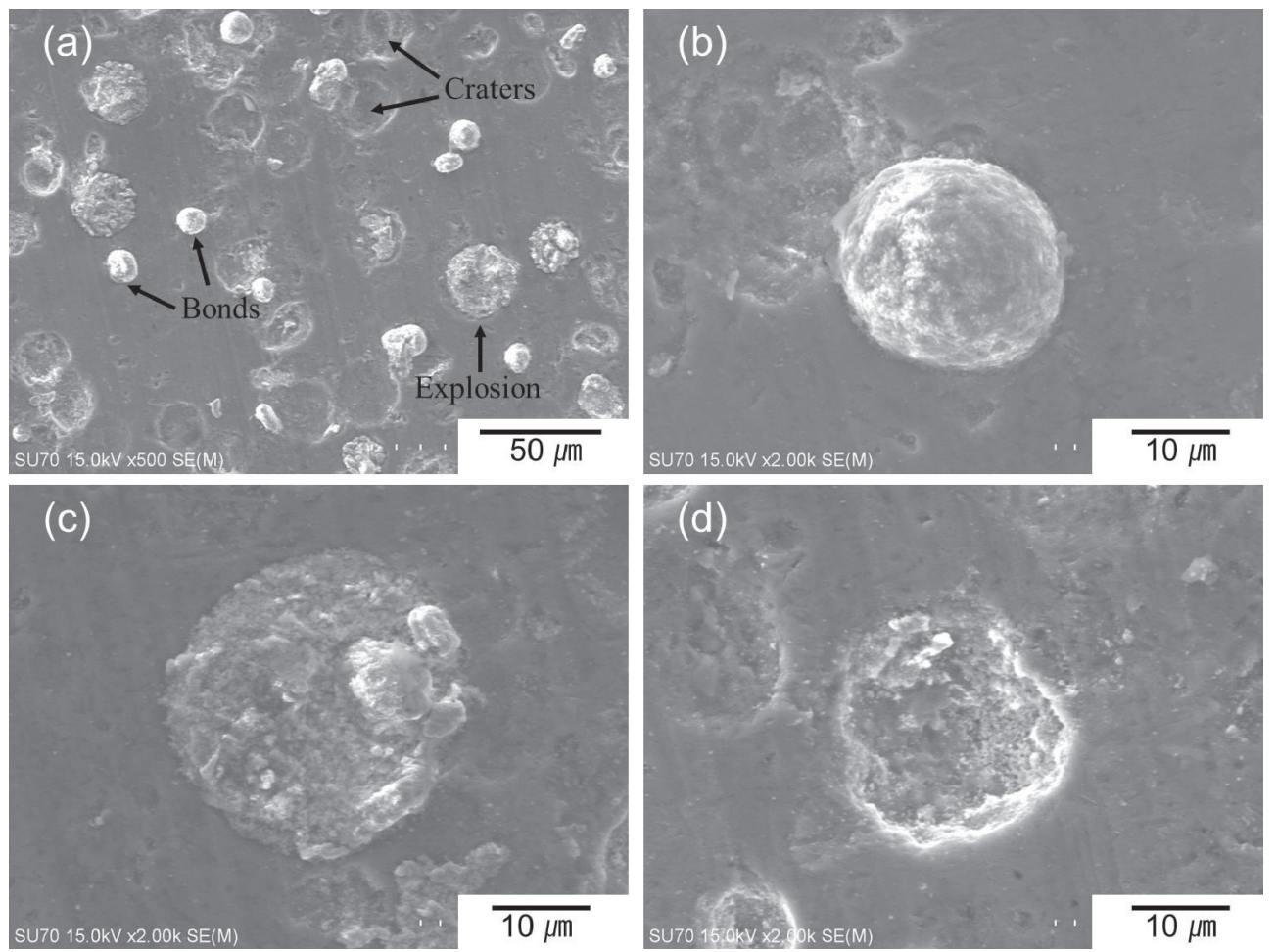

Fig. 7 The morphology of as-sprayed 25Y-cermet particles on Al substrate: (a) as-sprayed particles; (b) bonded particle; (c) exploded particle, and (d) rebounded particle.
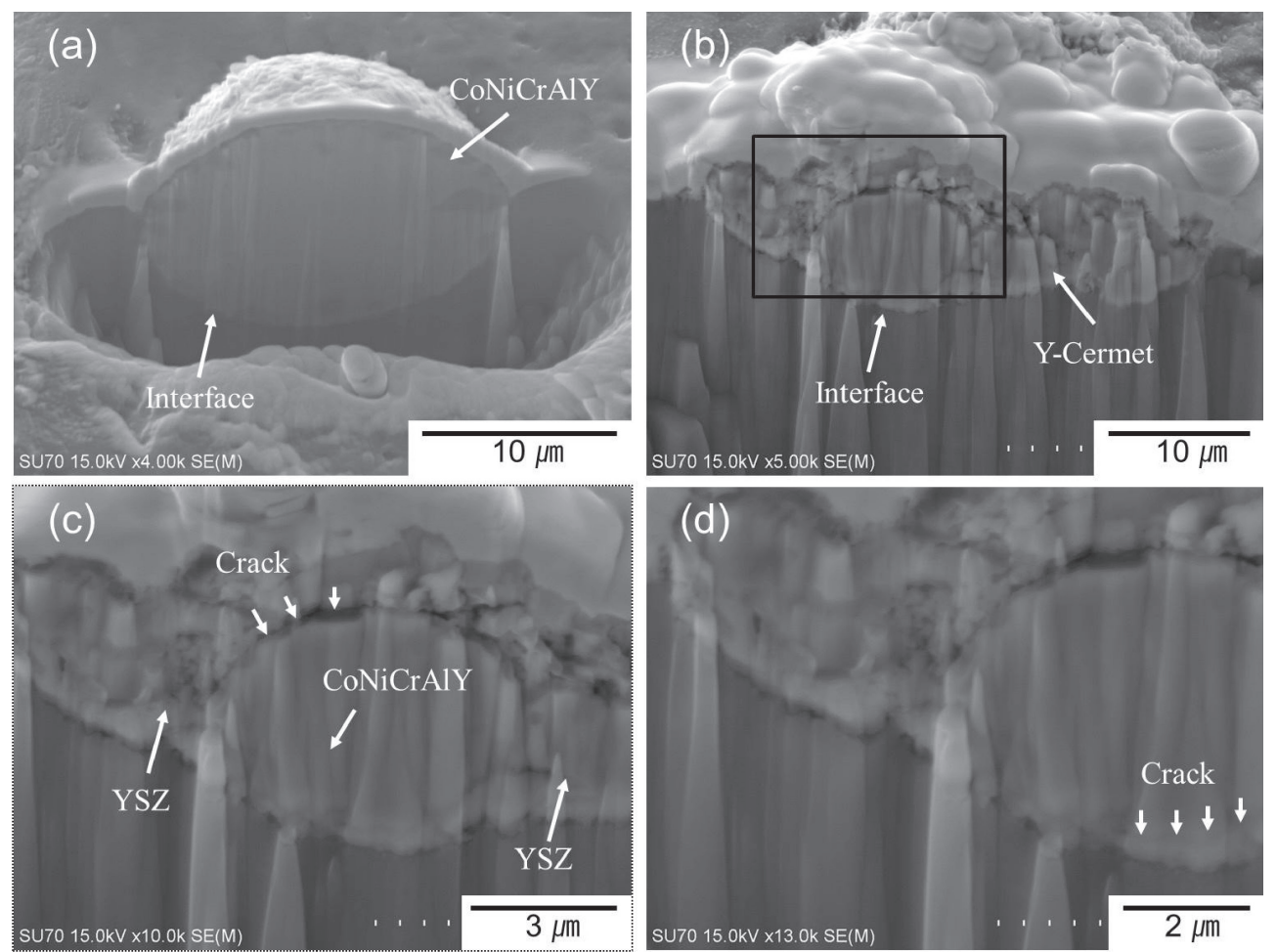

Fig. 8 Cross-sectional micrographs of (a) CoNiCrAlY particle, (b) Y-cermet particle at $5000 \times$, (c) Y-cermet particle at $10000 \times$, and

(d) Y-cermet particle at $13000 \times$.

ductility. Some materials coated by cold-spraying are also only capable of deposition in very specific circumstances. With the Y-cermet powder, although the particles are destroyed by their high collision energy, cold-spraying can successfully deposit ceramic materials with metallic materi- als. As shown in Fig. 8(b), the Y-cermet particle is deposited over a wide area; cracks inside of the particle are observed. In the EDX results, cracks were found between the nano-YSZ and CoNiCrAlY in the Y-cermet. After collision, the particle is crushed by its high impact energy. Additionally, in 


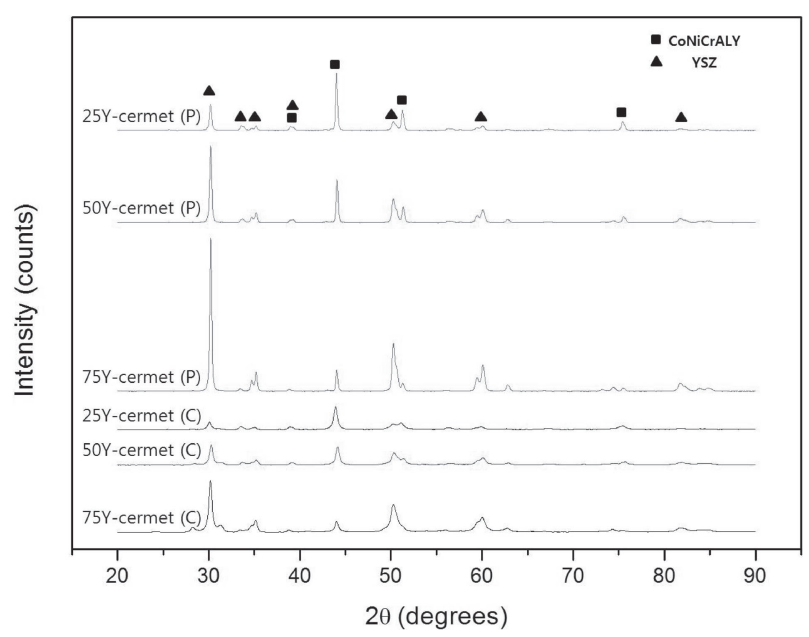

Fig. 9 XRD profiles of the Y-cermet powders (P) and the cold-sprayed Y-cermet coatings (C).

Fig. 8(d), nano-YSZ is confirmed to exist between the CoNiCrAlY particle and the Al substrate. After the collision, the CoNiCrAlY particle compresses the YSZ particle using the collision energy; consequently, this is expected to produce a denser coating.

\subsection{X-ray diffraction (XRD)}

$\mathrm{X}$-ray diffraction (XRD) analysis was used to determine the materials and phases present in both the mechanical powder blends and the fabricated coatings. Figure 9 shows the XRD spectra of the representative feedstock powders and coatings. Only peaks corresponding to phases of YSZ and CoNiCrAlY exist in the patterns of the as-sprayed coatings, identical to those of the feedstock powders. This suggests that no phase transformation occurs in the cold-spraying of Y-cermets under our experimental conditions. Moreover, no metal oxidation is observed at the cold-sprayed deposited surface, as a result of its low deposition temperature and the inert gas atmosphere $\left(\mathrm{N}_{2}\right)$ of the process. XRD also provides the relative amounts of materials present in a given mixture. The primary peaks of YSZ and CoNiCrAlY are at the $2 \theta$ angles of approximately $30^{\circ}$ and $44^{\circ}$, respectively.

\section{Conclusions}

In the present study, the mechanically agglomerated and sintered cermet powders of YSZ/CoNiCrAlY and its coldsprayed coatings were investigated.

The Y-cermet powder containing well-distributed YSZ powders was successfully deposited by the cold-spray process. The results showed a homogeneous microstructure because the feedstock powders were mechanically blended and agglomerated to form the spray particles. Moreover, no metal oxidation was found at the cold-sprayed deposited surface, as a result of the reaction's low temperature and inert gas atmosphere $\left(\mathrm{N}_{2}\right)$. In hardness testing results, the hardness of the coating deposited by cold-spraying exceeded that of the powder by close to a factor of 5. This indicated that the Y-cermet increased in hardness compression during its deposition by cold-spraying. However, the different mixtures of Y-cermet powders showed properties of hardness and deposition efficiency depending on their YSZ contents. Therefore, different manufacturing conditions are necessary to obtain the highest-quality coatings, depending on the YSZ contents. Consequently, the cold-spray system is a suitable method to manufacture FGM-TBCs using Y-cermet powders, especially considering its low cost and simplicity. However, some remaining problems, such as the formation of pores formation and generation of cracks by high pressure, must be solved before this process is implemented commercially.

\section{REFERENCES}

1) A. Manap, A. Nakano and K. Ogawa: J. Therm. Spray Technol. 21 (2012) 586-596.

2) D. Seo, K. Ogawa, Y. Nakao, H. Miura and T. Shoji: Surf. Coat. Technol. 203 (2009) 1979-1983.

3) M. Okazaki, S. Yamagishi, Y. Yamazaki, K. Ogawa, H. Waki and M. Arai: Int. J. Fatigue 53 (2013) 33-39.

4) Y. Li, C. Li, G. Yang and L. Xing: Surf. Coat. Technol. 205 (2010) 2225-2233.

5) P. Puetz, X. Huang, R. S. Lima, Q. Yang and L. Zhao: Surf. Coat. Technol. 205 (2010) 647-657.

6) A. C. Karaoglanli, H. Dikici and Y. Kucuk: Eng. Fail. Anal. 32 (2013) 16-22.

7) J. Toscano, R. Vaben, A. Gil, M. Subanovic, D. Naumenko, L. Singheiser and W. J. Quadakkers: Surf. Coat. Technol. 201 (2006) 3906-3910.

8) Y. W. Gu, K. A. Khor, Y. Q. Fu and Y. Wang: Surf. Coat. Technol. 96 (1997) 305-312.

9) G. Shanmugavelayutham and A. Kobauashi: Mater. Chem. Phys. 103 (2007) 283-289.

10) A. Kawasaki and R. Watanabe: Eng. Fract. Mech. 69 (2002) 17131728 .

11) K. A. Khor and Y. W. Gu: Thin Solid Films 372 (2000) 104-113.

12) J. H. Kim, M. C. Kim and C. G. Park: Surf. Coat. Technol. 168 (2003) 275-280.

13) A. Papyrin, V. Kosarev, S. Klinkov, A. Alkhimov and V. Fomin: Cold Spray Technology, (Elsevier, Russia, 2007) pp. 119-124.

14) H. Lee, H. Shin, S. Lee and K. Ko: Mater. Lett. 62 (2008) 1579-1581.

15) H. Kang and S. Kang: Scr. Mater. 49 (2003) 1169-1174.

16) S. V. Klinkov, V. F. Kosarev, A. A. Sova and I. Smurov: Surf. Coat. Technol. 202 (2008) 5858-5862.

17) F. F. Khan, G. Bae, K. Kang, S. Kumar, T. Jeong and C. Lee: Surf. Coat. Technol. 204 (2009) 345-352.

18) S. Dosta, M. Couto and J. M. Guilemany: Acta Mater. 61 (2013) 643652.

19) M. Winnicki, A. Malachowska, M. Rutkowska-Gorczyca, P. Sokolowski, A. Ambroziak and L. Pawlowski: Surf. Coat. Technol. 268 (2015) 108-114. 